\title{
Human Neonatal Peripheral Blood Leukocytes Demonstrate Pathogen-Specific Coordinate Expression of TLR2, TLR4/MD2, and MyD88 During Bacterial Infection In Vivo
}

\author{
JIN-PING ZHANG, YI YANG, OFER LEVY, AND CHAO CHEN \\ Division of Neonatology [J.-P.Z., Y.Y., C.C.], Children's Hospital of Fudan University, Shanghai 201102, People's Republic of China; \\ Division of Infectious Diseases [O.L.], Children's Hospital Boston, Harvard Medical School, Boston, Massachusetts 02115
}

\begin{abstract}
Toll-like receptors (TLRs) play important roles in infection. We have previously reported TLR2 is up-regulated in neonatal Gram-positive $(\mathrm{G}+)$ bacteremia, whereas TLR4 is upregulated in neonatal Gram-negative $\left(\mathrm{G}^{-}\right)$bacteremia. For functional signaling, TLR4 requires myeloid differentiation (MD)-2, and both TLR2 and TLR4 signal need myeloid differentiation factor (MyD88). However, it is unknown whether newborns can enhance expression of MD-2 and MyD88 with bacterial infection in coordination with TLR expression. We characterized neonatal peripheral blood leukocyte expression of MD-2 and MyD88 in relation to TLR2/4 in newborns. TLR 2 mRNA expression by PBMCs and TLR2 protein expression by monocytes and granulocytes were significantly increased in the $\mathrm{G}+$ bacteremia group. TLR4 mRNA on PMBCs and protein expression on monocytes and granulocytes were significantly increased in the G- bacterial group. Remarkably, although, MyD88 mRNA was increased in all patients with documented bacterial infection and correlated with both TLR2 and TLR4, MD-2 mRNA was selectively increased in $\mathrm{G}-$ bacterial group, wherein it correlated with TLR4 but not with TLR2 mRNA. Our findings demonstrate that during bacterial infection in vivo, newborns selectively and coordinately amplify the TLR2-MyD88 pathway in G+ bacterial infection and the TLR4/ MD2/MyD88 pathway in G- bacterial infection, suggesting key roles for innate immune pathway in neonatal responses to bacterial infection. (Pediatr Res 68: 479-483, 2010)
\end{abstract}

$\mathrm{B}$ acterial infections remain a leading cause of neonatal morbidity and mortality, especially among premature neonates. The mechanisms of immune function in newborns are not completely understood. It is assumed that high susceptibility of newborns to infections is because of the functional immaturity of innate and adaptive immune responses (1). The innate immune response is important in the early stages of defense against bacterial pathogens. Defense against pathogens is, in part, based on leukocytes, such as granulocytes and monocytes, which express pattern recognition receptors (PRRs) that recognize specific structures present on microorganisms, termed pathogen-associated molecular pat-

Received March 4, 2010; accepted August 10, 2010.

Correspondence: Chao Chen, M.D., Ph.D., Division of Neonatology, Children's Hospital of Fudan University, Wanyuan Road 399, Minhang District, Shanghai 201102, People's Republic of China; e-mail: chen6010@163.com

Supported by Chinese Education Ministry 211 Project and the New Teacher Foundation of the Ministry of Education of China (20090071120078); Children's Hospital of Fudan University. O.L. is supported by a Grant NIH RO1 AI067353-01A1 and by the Bill \& Melinda Gates Foundation.

O.L. and C.C. contributed equally to this work. terns (PAMPs) (2,3). Among the PRRs are the toll-like receptors (TLRs), whose importance as sentinel receptors has been increasingly appreciated $(4,5)$. Eleven TLRs have been identified in mammals that recognize different PAMPs present in bacteria and viruses, among which TLR 2 and TLR4 are the most widely studied (6). Multiple studies have shown that TLR2 mainly responds to Gram-positive $(\mathrm{G}+)$ bacterial peptidoglycan (7) and TLR4 mainly recognizes Gram-negative $(\mathrm{G}-)$ bacterial lipopolysaccharides (LPS) (8). LPS is one of the best-characterized PAMPs that bind to the CD14/TLR4/ MD-2 receptor complex (9). CD14 binds to LPS but lacks an intracellular component and is, thus, incapable of signaling. Myeloid differentiation (MD)-2 is a protein necessary for LPS recognition by TLR4. MD-2 binds on TLR4 in the endoplasmic reticulum/cis-Golgi and then the TLR4-MD-2 complex moves to the cell surface (10). LPS binds MD-2 triggering changes in MD-2 conformation that are detected by TLR4 (11). Engagement of TLR4 activates intracellular signaling via the adapter protein myeloid differentiation factor 88 (MyD88) (12), ultimately leading to intracellular activation of mitogenactivated protein kinase and nuclear factor- $\kappa \mathrm{B}$ that activate transcription of cytokine and chemokine genes (13).

Most studies of the functional expression of the TLR system have been performed in samples derived from murine or human adults. Studies of neonatal mice and human neonatal cord blood have demonstrated GA-dependent increases in expression of functional TLR4 during gestation $(14,15)$. Studies of basal and LPS-induced TLR4 expression on neonatal blood monocytes demonstrate expression of TLR4 at birth and some ability of neonatal cells to up-regulate TLR4 in vitro but have provided contradictory data with respect to quantitative comparisons with adult cells $(14,16-21)$. TLR4 expression in neonatal cord blood monocytes increases in a GA-dependent manner, whereas that of TLR2 does not (22). Unstimulated human newborn cord blood monocytes express TLRs and MyD88 at birth $(16,23)$. Basal expression of TLR2 is slightly lower in neonatal phagocytes compared with adults (17).

\footnotetext{
Abbreviations: G-, Gram-negative; G+, Gram-positive; MD-2, myeloid differentiation protein-2; MFI, mean fluorescence intensity; MyD88, myeloid differentiation 88; PAMPs, pathogen-associated molecular patterns; PBMCs, peripheral blood mononuclear cells; PRRs, pattern recognition receptors; TLRs, toll-like receptors
} 
Compared with the many studies of TLR expression in vitro, much less is known about the ability of human newborns to modulate TLR system expression in vivo. A study of human neonatal sepsis, largely defined by clinical parameters with a preponderance of $\mathrm{G}+$ bacteria in the culture-positive cases, found marked up-regulation of TLR2 on monocytes, with only transiently increased TLR2 expression on granulocytes (17). We have previously shown that human newborn peripheral blood mononuclear cells (PBMCs) selectively up-regulated TLRs during bacteremia such that TLR2 was up-regulated with $\mathrm{G}+$ bacteremia and TLR4 was up-regulated with $\mathrm{G}-$ bacteremia (24). As TLR2 and TLR4 require partnering molecules to facilitate their function, in this study, we characterized expression of TLRs, MD-2, and MyD88 on human neonatal peripheral blood leukocytes and investigated their relationships to infection. We found that human newborns demonstrate selective and coordinated expression of TLR2 and TLR4/MD-2 as well as MyD88 in a pathogen-specific manner, providing new insights into the neonatal response to bacterial infection.

\section{MATERIALS AND METHODS}

Study design and population. We enrolled 83 neonates with bacterial infection and 43 neonates without infection, who were admitted to the neonatal intensive care unit of the Children's Hospital of Fudan University, Shanghai, China, during 2004 to 2006. We used the following exclusion and inclusion criteria: a) exclusion criteria: neonates with evidence of major congenital malformations, inborn errors of metabolism, and those who had received immunotherapy were excluded from enrollment. None of the neonates exhibited signs of hypoxia or asphyxia. All those neonates with mothers who have history of infection, HIV, exposure of steroids, and maternal history of autoimmune disease, and smoking were also excluded. b) Inclusion criteria: all infants who were vaginally delivered. At the time of admission, neonates were suspected to have infection if they had clinical symptoms (apnea, bradycardia, instability of body temperature, feeding intolerance or desaturation, and so on) and at least one abnormal test result [high C-reactive protein (CRP), high ratio of immature total neutrophils, and abnormal x-ray]. Blood, urine, and cerebrospinal fluid cultures and blood samples for TLR pathway analysis were obtained before initiating antibiotic therapy. Patients with positive culture results were then enrolled in this study. Tracheal aspirate cultures were taken from neonates who were intubated and had abnormal chest radiographs. Patients with positive tracheal aspirate cultures were included in this analysis only if they had accompanying chest radiograph abnormalities. All those patients were successfully treated by supportive and standard antibiotic treatment after all these blood samples were taken; none of them received any steroids or immune modulators.

We have previously reported up-regulation of TLR2 and TLR4 in neonates with bacteremia and in those with clinical infection of any site (including pneumonia, meningitis, and urinary tract infection) but did not analyze TLR expression in the infected group with respect to microbiologic culture, i.e. we had not compared data for $\mathrm{G}-$ or $\mathrm{G}+$ bacterial infection (24). In this study, we focused only on those patients with positive cultures from the previous study and an additional two patients, both with Klebsiella pneumoniae bacteremia. In addition, we measured MD-2 and MyD88 mRNA expression for all patients with positive culture. In total, we analyzed neonates in three groups: control $(n=43), \mathrm{G}+$ infection $(n=41)$, and $\mathrm{G}-$ infection $(n=42)$.

Blood samples for RNA analysis. One milliliter venous blood was collected by peripheral venipuncture into heparinized tubes (QDKY, Qingdao, Shandong, China) and diluted 1:1 in endotoxin-free Hanks' balanced salt solution (HBSS). A total of $5 \times 10^{6}$ PBMCs were isolated by Ficoll gradient centrifugation, washed three times with ice cold endotoxin-free HBSS, and immediately lysed in $1 \mathrm{~mL}$ Trizol reagent (Invitrogen, Carlsbad, CA). The control group comprised blood samples obtained from neonates whose blood was taken for the screening of inborn errors of metabolism $(n=39)$ or at the time of routine electrolyte testing $(n=4)$.

Whole blood flow cytometry. Flow cytometry was used to measure cell surface TLR expression. Whole blood samples $(0.5 \mathrm{~mL}$, anticoagulated with EDTA) were stained for $20 \mathrm{~min}$ at $4^{\circ} \mathrm{C}$ in the dark with isotype-matched control antibodies (BD PharMingen, SanDiego, CA), a FITC-conjugated
CD14 MAb (MAb; clone M-P9; BD Phar-Mingen), and phycoerythrin (PE)conjugated mouse anti-human TLR2 or -4 IgG2a mAbs (clones TL2.1 or HTA125, respectively), or corresponding isotype control mAbs (eBioscience, Frederick, MD). Measurements were performed using a FACS Calibur flow cytometer and data acquired by Cell Quest software (BD Biosciences, Franklin Lakes, NJ). Granulocytes and monocytes were differentiated by scatter properties and CD14 expression (high in monocytes and low in granulocytes). Mean fluorescence intensities (MFIs) were determined by subtracting the fluorescence intensity of the isotype control mAbs from that of the specific mAbs. We defined the MFI shift as the ratio of the MFI of the marker to the MFI of the isotype control. We also measured the percentage of TLR2- and TLR4-positive cells on monocytes and granulocytes.

Quantitative RT-PCR. Total RNA was isolated from PBMCs and extracted by Trizol. All reagents and devices used for PCR were obtained from Applied Biosystems. A total of $200 \mathrm{ng}$ of RNA was reverse transcribed to cDNA using TaqMan reverse transcription agents. Quantitative RT-PCR of target CDNA was conducted for TLR, MyD88, and MD-2, and values were normalized to $\beta$-actin gene expression. Primer and probes were from the TaqMan Gene Expression Assays. Experiments were performed in 96-well plates in triplicate using TaqMan Universal Master Mix. RT-PCR amplification was performed on a Gene Amp7700 Sequence Detection System. PCR conditions were $50^{\circ} \mathrm{C}$ for 2 min and $95^{\circ} \mathrm{C}$ for $10 \mathrm{~min}$ and then 45 cycles at $95^{\circ} \mathrm{C}$ for $15 \mathrm{~s}$ and $60^{\circ} \mathrm{C}$ for $1 \mathrm{~min}$. mRNAs encoding $\beta$-actin, TLR, MyD88, and MD-2 were amplified using the primers shown in Table 1 .

Statistical analysis. Data are presented as mean \pm SD. Groups were compared using the $t$ test and the Mann-Whitney test. Correlations between individual parameters were determined using a Spearman rank correlation. All comparisons were made using two-sided significance levels of $p<0.05$. Statistical analyses were performed using SPSS 12.0 (SPSS China, Shanghai, China).

Ethical approval. The study was approved by the Children's hospital of Fudan University Research Ethical Committee, and informed written parental consent was obtained before neonates were entered into the study.

\section{RESULTS}

Study population. From January 2004 to January 2006, a total of 126 neonates who had been referred to the neonatal care unit of the Children's Hospital of Fudan University, Shanghai, People's Republic of China, were included. Fortythree neonates were included in the noninfection group, 41 neonates in the $\mathrm{G}+$ bacterial infection group, and 42 neonates in the $\mathrm{G}-$ bacterial infection group. The groups were matched for GA, birth weight, and the time of infection. A total of 67 preterm infants and 59 term infants were included. Most term infants were near $37 \mathrm{wk}$, their mean GA was $38.1 \pm 1.1 \mathrm{wk}$, and there were no postdates neonates. Control samples were matched according to the age at entry of the study. The relevant clinical characteristics of the 126 infants are shown in Table 2. Bacteria isolated from positive cultures are shown in Table 3.

Expression of TLR2, TLR4, MD-2, and MyD88 mRNA. In the control group, TLR2 and TLR4 mRNA expression were $5.05 \pm 0.88$ and $4.93 \pm 1.30$ (arbitrary units and ratio TLR

Table 1. Primers for $\beta$-actin, TLR, MyD88, and MD-2 mRNA

\begin{tabular}{|c|c|}
\hline & PCR primers \\
\hline$\beta$-actin forward & 5'-CACCAACTGGGACGACAT-3' \\
\hline$\beta$-acti & 5'-ATCTGGGTCATCTTCTC \\
\hline & 5'-CTGCAAGCTGCGGAAC \\
\hline TLR2 & 5'-GTTACGAAGAGGCTGGAATGGT-3' (176bp) \\
\hline & $5^{\prime}$-GATTGCTCAGACCTGC \\
\hline TLR4 reverse & 5'-TGTCCTCCCACTCCAGGTAAGT-3' (143 bp) \\
\hline & 5'-CATTCCAAGGAGAGATTTAAAGCAA-3' \\
\hline MD- & 5'-CAGATCCTCGGCAAATAACTTCTT-3' (104bp) \\
\hline & $5^{\prime}$-GGATCTTGGGAGGGAATGGA-3' \\
\hline MyD88 reverse & 5'-GAGATGGCTTTAAAATGCCCAGTA-3' (168bp) \\
\hline
\end{tabular}


Table 2. Characteristics of the neonatal study subjects*

\begin{tabular}{lccccc}
\hline \multicolumn{1}{c}{ Groups } & $n$ & Preterm/term & GA (wk) & $\begin{array}{c}\text { Birthweight } \\
(\mathrm{kg})\end{array}$ & $\begin{array}{c}\text { Age at study } \\
\text { enrollment }(\mathrm{d})\end{array}$ \\
\hline Control & 43 & $21 / 22$ & $35.05 \pm 2.71$ & $2.56 \pm 1.19$ & $5.47 \pm 6.97$ \\
G+ group & 42 & $23 / 19$ & $33.12 \pm 3.84$ & $2.04 \pm 0.84$ & $6.33 \pm 7.72$ \\
G- group & 41 & $23 / 18$ & $34.05 \pm 4.56$ & $2.12 \pm 1.12$ & $8.0 \pm 7.49$ \\
\hline
\end{tabular}

* There were no significant differences between the control group and the infection groups.

Table 3. Bacteria isolated from the study subjects

\begin{tabular}{|c|c|c|}
\hline Sample(n) & Gram-positive bacteria $(\mathrm{N})$ & Gram-negative bacteria $(\mathrm{N})$ \\
\hline $\begin{array}{l}\text { Blood } \\
\quad \text { sample } \\
\quad(23)\end{array}$ & $\begin{array}{l}\text { Coagulase-negative } \\
\text { Staphylococci (4), } \\
\text { Enterococcus faecalis (2), } \\
\text { Streptococcus spp. (3) }\end{array}$ & $\begin{array}{l}\text { Klebsiella pneumoniae (8), } \\
\text { Pseudomonas aeruginosa (2), } \\
\text { Enterobacter cloacae (4) }\end{array}$ \\
\hline $\begin{array}{l}\text { Tracheal } \\
\text { aspirate } \\
(46)\end{array}$ & $\begin{array}{l}\text { Coagulase-negative } \\
\text { Staphylococci (16), } \\
\text { E. faecalis (6), } \\
\text { Streptococcus spp. (5) }\end{array}$ & $\begin{array}{l}\text { K. pneumoniae }(8), \\
\text { P. aeruginosa }(6), \\
\text { E. cloacae }(5)\end{array}$ \\
\hline $\begin{array}{l}\text { Urine } \\
\text { sample } \\
\text { (11) }\end{array}$ & E. faecalis (6) & $\begin{array}{l}\text { K. pneumoniae }(2), \\
\text { E. cloacae }(3)\end{array}$ \\
\hline $\begin{array}{l}\text { Cerebral } \\
\quad \text { fluid (3) }\end{array}$ & (0) & E. cloacae (3) \\
\hline
\end{tabular}

mRNA/ $\beta$-actin), respectively (Fig. 1$)$. There were no correlations found between mRNA levels of TLR2, TLR4, MD-2, or MyD88 mRNA with GA $(r=0.11, p=0.82 ; r=0.04, p=0.82 ; r=$ $0.08, p=0.75$; and $r=0.054, p=0.85$, respectively).

The expression of TLR2 mRNA in the $\mathrm{G}+$ bacterial group was higher than the $\mathrm{G}-$ bacterial group $(t=2.28, p=0.03)$. Conversely, expression of TLR4 mRNA in the $\mathrm{G}-$ bacterial group was higher than the $\mathrm{G}+$ bacterial group $(t=2.29, p=$ 0.03). Expression of MyD88 mRNA in each of the infection groups was higher than the control group but did not significantly differ between the $\mathrm{G}+$ bacterial and the $\mathrm{G}-$ bacterial group ( $t=0.79, p=0.86$ ). MD-2 mRNA expression in the $\mathrm{G}-$ group was higher than in the $\mathrm{G}+$ bacterial group $(p<0.05)$.

Expression of TLR2 and TLR4 proteins on granulocytes and monocytes. In the control group, $72 \pm 21 \%$ of monocytes were TLR2+ with an MFI of $1.27 \pm 0.75$. There was no significant correlation between either percentage or MFI of TLR2 with GA ( $r=0.03, p=0.87$ and $r=0.08, p=0.70$, respectively). A total of $49 \pm 11 \%$ of monocytes were TLR4+ with an MFI of $1.16 \pm 0.36$, neither of which correlated with GA $(r=0.19, p=0.45$ and $r=0.14, p=$ 0.58 , respectively); $30 \pm 10 \%$ of granulocytes in controls were TLR2+ with an MFI of $0.31 \pm 0.25$. There was no significant correlation between either percentage or MFI of TLR2 with GA $(r=0.02, p=0.92$ and $r=0.001, p=0.95$, respectively); $21.12 \pm 11.13 \%$ of granulocytes were TLR4+ with an MFI of $1.21 \pm 0.55$, neither of which correlated with GA ( $r=0.04, p=0.65$ and $r=0.05, p=0.42$, respectively).

Monocyte and granulocyte TLR2 expression (MFI) was higher in the $\mathrm{G}+$ bacterial group than $\mathrm{G}-$ bacterial group and control group ( $p<0.05 ;$ Fig. 2$)$. Monocyte and granulocyte TLR4 MFI was higher in the $\mathrm{G}-$ group than in the control and the $\mathrm{G}+$ bacterial group $(p<0.05$; Fig. 2). The average

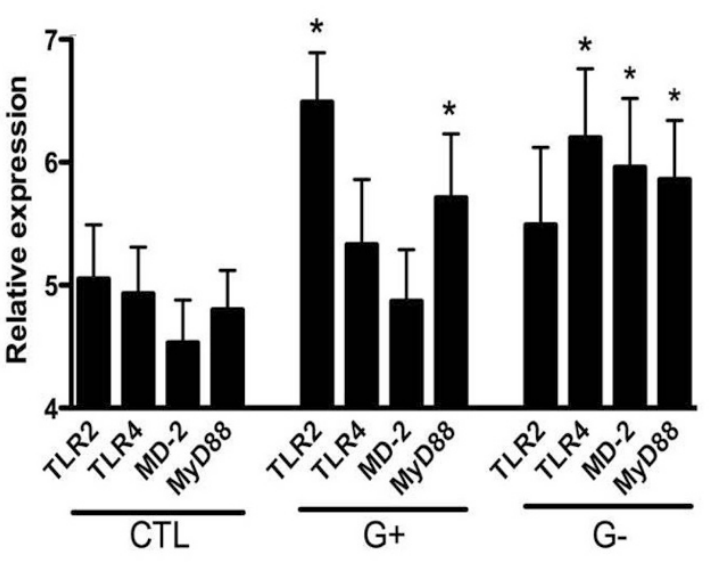

Figure 1. mRNA expression of TLR2, TLR4, MD-2, and MyD88 in control newborns in comparison with those with Gram + or Gram- infection. Peripheral blood was collected from control or infected newborns and analyzed for mRNA expression of TLR2, TLR4, MyD88, and MD-2 as described in Methods. Data represent mean $\pm \mathrm{SD} ;{ }^{*} p<0.05$, when compared with the control group using $t$ test.

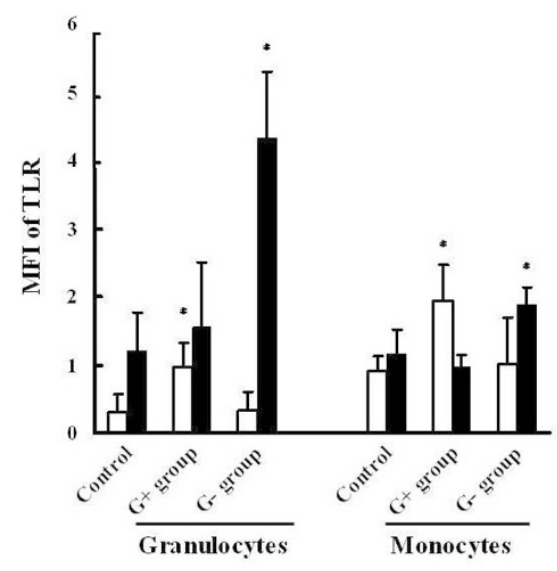

Figure 2. MFI of TLR2 and TLR4 on the granulocytes and monocytes in control newborns in comparison with those with Gram+ or Gram - infection. Peripheral blood was collected from control or infected newborns and analyzed for MFI of TLR2 ( $\square$ ) and TLR4 ( $\square$ ) as described in Methods. Data represent mean $\pm \mathrm{SD} ; * p<0.05$, when compared with the control group using $t$ test.

percentage of monocytes and granulocytes that were TLR2+ and TLR4+ in the infection group were not different from the control group ( $p>0.05$; Table 4).

Relationships of MyD88 and MD-2 mRNAs with TLR expression. TLR4 mRNA and MFI were significantly correlated with MD-2 mRNA in the G- bacterial infection group ( $r=0.42$, $p=0.02$ and $r=0.54, p=0.01$, respectively). In each of the infection groups, TLR2 mRNA and TLR4 mRNA were significantly correlated with MyD88 mRNA $(r=0.95, p=0.001$ and $r=0.99, p=0.001$, respectively). Similarly, TLR2 and TLR4 proteins expression on monocytes (flow cytometry, MFI) were also significantly correlated with MyD88 mRNA ( $r=0.87, p=$ 0.001 and $r=0.91, p=0.001$,respectively). Among the $\mathrm{G}-$ and $\mathrm{G}+$ bacterial infection groups, there was no significant correlation between TLR2 expression (MFI or mRNA) and MD-2 expression (mRNA): $r=0.24, p=0.07$ and $r=0.12, p=0.12$, respectively. 
Table 4. Percentage of TLR2 and TLR4 positive cells on monocytes and granulocytes

\begin{tabular}{lccccc}
\hline \multicolumn{1}{c}{ Groups } & $n$ & $\begin{array}{c}\text { Percentage of TLR2 positive } \\
\text { cell }(\%) \text { on monocytes }\end{array}$ & $\begin{array}{c}\text { Percentage of TLR2 positive } \\
\text { cell }(\%) \text { on granulocytes }\end{array}$ & $\begin{array}{c}\text { Percentage of TLR4 positive } \\
\text { cell (\%) on monocytes }\end{array}$ & $\begin{array}{c}\text { Percentage of TLR4 positive } \\
\text { cell (\%) on granulocytes }\end{array}$ \\
\hline Control & 43 & $72.02 \pm 21.41$ & $30.1 \pm 10.21$ & $49.21 \pm 11.23$ & $21.12 \pm 11.13$ \\
G+ group & 42 & $75.7 \pm 15.16$ & $32.4 \pm 12.36$ & $54.13 \pm 13.44$ & $24.15 \pm 13.64$ \\
G- group & 41 & $72.39 \pm 18.71$ & $28.9 \pm 11.74$ & $62.53 \pm 15.16$ & $21.96 \pm 12.45$ \\
\hline
\end{tabular}

\section{DISCUSSION}

Neonates, and in particular preterm newborns, are susceptible to bacterial infections, which cause significant mortality and morbidity annually. Despite considerable advances in neonatal intensive care medicine, the incidence of infection is still very high. The pathogenesis of neonatal infection with its rapid progression from infection to a systemic inflammatory response still remains unclear. The characterization over the past two decades of PRRs based on insect and animal models and in vitro studies of human cells has informed novel concepts regarding the pathogenesis of infection. The immature innate immune system plays a key role in the first line of defense against invading microbes in neonates (1). In this study, we characterized human neonatal peripheral blood leukocyte expression of MyD88 and MD-2 in relation to TLR expression and bacterial infections.

The frequent exposure to invasive procedures in neonatal intensive care units such as umbilical and intravascular catheterization, intubation, and long-term ventilation play roles in the high neonatal infections (25). Reduced levels of TLR4 expression and impaired TLR-mediated production of $\mathrm{T}_{\mathrm{H}} 1$ polarizing cytokines might also contribute to neonatal susceptibility to bacterial infection (22). A study of blood leukocyte TLR expression after endotoxin infusion in human adults in vivo demonstrated up-regulation of TLR2 (but not TLR4) on monocytes and down-regulation of TLR4 (but not TLR2) on neutrophils (26). TLR-signaling pathway genes are differently regulated in PBMCs and neutrophils of adult patients with clinical sepsis (27). However, TLR2, TLR4, and MyD88 mRNA, all increased in adult sepsis mainly because of G+ bacteria (27). In accordance with our findings in neonates, a study of adult $\mathrm{G}-$ bacterial sepsis demonstrated elevations of TLR4 and soluble MD-2 on endothelial cells (28).

Multiple studies have established that TLR4 requires MD-2 to mediate LPS signaling (29-31). Our data show significant correlations between the mRNA expression of MD-2 and TLR4, suggesting coordinate expression of these coreceptors on the cell surface during $\mathrm{G}-$ bacterial infection.

MyD88-deficient mice are highly susceptible to infections with a broad range of microorganisms (32), and reduced MyD88 expression levels might contribute to impaired neonatal immune responses to pathogens (18). However, our study did not demonstrate any correlation between MyD88 mRNA and GA. We demonstrated that MyD88 mRNA expression increased greatly in both bacterial infection groups. There are at least two pathways downstream of TLR activation: the MyD88-dependent and the MyD88-independent pathways. Given the brisk up-regulation of MyD88 in the context of bacterial infection, the MyD88 pathway may play an important role in neonatal infections. Indeed, study of patients deficient in MyD88 or IRAK4 demonstrates that the TLR pathway is particularly important early in life, as susceptibility to pyogenic infection in these patients diminishes and normalizes with age $(33,34)$.

In this study, the basal expression of TLR2, TLR4, MyD88, and MD-2 were similar in preterm and full-term neonates at both the mRNA and protein level. A previous study demonstrated similar basal TLR2 and TLR4 expression between neonatal cord blood and adult peripheral blood (24). These results indicate that infection status, more than GA, is a key parameter effecting TLR2 and TLR4 expression, suggesting potential utility of TLR measurement as a biomarker of sepsis. We also measured TLR2 and TLR4 expression on neonatal granulocytes and monocytes. We analyzed the MFI of TLR2 and TLR4 and found that TLR2 MFI expression was upregulated in the $\mathrm{G}+$ bacterial infection group on both monocytes and granulocytes compared with the control group. In contrast, TLR4 protein expression (MFI) was up-regulated in the $\mathrm{G}-$ bacterial infection group on both monocytes and granulocytes. We also characterized expression levels of TLR2 and TLR4, demonstrating that human newborn peripheral blood monocytes expressed higher levels of TLR2 and TLR4 than granulocytes. In addition to the analysis of surface TLR expression on leukocytes, we also analyzed the TLR mRNA and its signaling pathways in culture-positive neonatal infections. We found that peripheral blood TLR2 and TLR4 mRNAs significantly increased in neonatal infections. Furthermore, TLR2 was increased in the setting of G+ bacterial infection, whereas TLR4 mainly increased in the setting of to $\mathrm{G}-$ bacterial infection, consistent with the results of our previous study (35). With respect to the absolute increases in TLR expression by flow, we demonstrate significant increases in MFI of $\sim 110 \%$ for TLR2 on monocytes in the setting of $\mathrm{G}+$ infection and $\sim 60 \%$ for TLR4 on monocytes in the context of $\mathrm{G}-$ infection. The relationships between absolute surface expression of TLRs and functionality are incompletely characterized and may be nonlinear, because dimerization/ multimerization of the receptors is known to be important for signaling (35).

In conclusion, our study reveals that during bacterial infections, human neonatal blood leukocytes demonstrate pathogen-specific and coordinated up-regulation of TLR2, TLR4/ MD-2, and the MyD88 adaptor molecule. Characterizing neonatal TLR pathway expression provides insights into the development of neonatal innate immune function and host defense against infection. Indeed, adjunctive therapy with TLR-based immunomodulators has demonstrated reduction of mortality after polymicrobial peritonitis in a neonatal animal model (36). A better understanding of neonatal host defense 
mechanisms may, thus, lead not only to improved diagnostics but also to preventative and therapeutic options or both (37).

Acknowledgments. We thank the patients and their families for their participation in this study. We thank Liat StolerBarakZhiheng Huang and Jianguo Zhou for assistance with data analysis.

\section{REFERENCES}

1. Levy O 2007 Innate Immunity of the human newborn: basic mechanisms and clinical correlates. Nat Rev Immunol 7:379-390

2. Medzhitov R 2007 Recognition of microorganisms and activation of the immune response. Nature 449:819-826

3. Jenkins KA, Mansell A 2010 TIR-containing adaptors in toll-like receptor signalling. Cytokine 49:237-244

4. Strunk T, Temming P, Gembruch U, Reiss I, Bucsky P, Schultz C 2004 Differential maturation of the innate immune response in human fetuses. Pediatr Res 56:219-226

5. Medzhitov R, Preston-Hurlburt P, Janeway CA Jr 1997 A human homologue of the Drosophila toll protein signals activation of adaptive immunity. Nature 388:394-397

6. Yamamoto M, Sato S, Hemmi H, Hoshino K, Kaisho T, Sanjo H, Takeuchiet O 2003 Role of adaptor TRIF in the MyD88-independent toll-like receptor signaling pathway. Science 301:640-643

7. Underhill DM, Ozinsky A, Smith KD, Aderem A 1999 Toll-like receptor-2 mediates mycobacteria-induced proinflammatory signaling in macrophages. Proc Natl Acad Sci U S A 96:14459-14463

8. Poltorak A, He X, Smirnova I, Liu M-Y, Van Huffel C, Du X, Birdwell D, Alejos E, Silva M, Galanos C 1998 Defective LPS signaling in C3H/HeJ and C57BL/ 10ScCr mice: mutations in Tlr4 gene. Science 282:2085-2088

9. Dobrovolskaia MA, Vogel SN 2002 Toll receptors, CD14, and macrophage activation and deactivation by LPS. Microbes Infect 4:903-914

10. Nishitani C, Mitsuzawa H, Hyakushima N, Sano H, Matsushima N, Kuroki Y 2005 The toll-like receptor 4 region Glu24-Pro34 is critical for interaction with MD-2. Biochem Biophys Res Commun 328:586-590

11. Gioannini TL, Teghanemt A, Zhang D, Coussens NP, Dockstader W, Ramaswamy S, Weiss JP 2004 Isolation of an endotoxin-MD-2 complex that produces toll-like receptor 4-dependent cell activation at picomolar concentrations. Proc Natl Acad Sci U S A 101:4186-4191

12. O'Neill LA 2006 How toll-like receptors signal: what we know and what we don't know. Curr Opin Immunol 18:3-9

13. Lakhani SA, Bogue CW 2003 Toll-like receptor signaling in sepsis. Curr Opin Pediatr 15:278-282

14. Förster-Waldl E, Sadeghi K, Tamandl D, Gerhold B, Hallwirth U, Rohrmeister K Hayde M, Prusa AR, Herkner K, Boltz-Nitulescu G, Pollak A, Spittler A 2005 Monocyte toll-like receptor 4 expression and LPS-induced cytokine production increase during gestational aging. Pediatr Res 58:121-124

15. Harju K, Glumoff V, Hallman M 2001 Ontogeny of toll-like receptors Tlr2 and Tlr4 in mice. Pediatr Res 49:81-83

16. Yan SR, Qing G, Byers DM, Stadnyk AW, Al-Hertani W, Bortolussi R 2004 Role of MyD88 in diminished tumor necrosis factor alpha production by newborn mononuclear cells in response to lipopolysaccharide. Infect Immun 72:1223-1229

17. Viemann D, Dubbel G, Schleifenbaum S, Harms E, Sorg C, Roth J 2005 Expression of toll-like receptors in neonatal sepsis. Pediatr Res 58:654-659

18. Henneke P, Osmers I, Bauer K, Lamping N, Versmold HT, Schumannet RR 2003 Impaired CD14-dependent and independent response of polymorphonuclear leukocytes in preterm infants. J Perinat Med 31:176-183

19. Qing G, Rajaraman K, Bortolussi R 1995 Diminished priming of neonatal polymorphonuclear leukocytes by lipopolysaccharide is associated with reduced CD14 expression. Infect Immun 63:248-252
20. Levy E, Xanthou G, Petrakou E, Zacharioudaki V, Tsatsanis C, Fotopoulos S, Xanthou M 2009 Distinct roles of TLR4 and CD14 in LPS-induced inflammatory responses of neonates. Pediatr Res 66:179-184

21. Yerkovich ST, Wikström ME, Suriyaarachchi D, Prescott SL, Upham JW, Holt PG 2007 Postnatal development of monocyte cytokine responses to bacterial lipopolysaccharide. Pediatr Res 62:547-552

22. Sadeghi K, Berger A, Langgartner M, Prusa AR, Hayde M, Herkner K, Pollak A, Forster-Waldl E 2007 Immaturity of infection control in preterm and term newborns is associated with impaired toll-like receptor signaling. J Infect Dis 195:296-302

23. Levy O, Zarember KA, Roy RM, Cywes C, Godowski PJ, Wessels MR 2004 Selective impairment of TLR-mediated innate immunity in human newborns: neonatal blood plasma reduces monocyte TNF-alpha induction by bacterial lipopeptides, lipopolysaccharide, and imiquimod, but preserves the response to R-848. J Immunol 173:4627-4634

24. Zhang JP, Chen C, Yang Y 2007 [Changes and clinical significance of toll-like receptor 2 and 4 expression in neonatal infections]. Zhonghua Er Ke Za Zhi 45:130-133

25. Orsi GB, d'Ettorre G, Panero A, Chiarini F, Vullo V, Venditti M 2009 Hospitalacquired infection surveillance in a neonatal intensive care unit. Am J Infect Control 37:201-203

26. Marsik C, Mayr F, Cardona F, Derhaschnig U, Wagner OF, Jilma B 2003 Endotoxaemia modulates toll-like receptors on leucocytes in humans. $\mathrm{Br} \mathrm{J}$ Haematol 121:653-656

27. Salomao R, Brunialti MK, Gomes NE, Mendes ME, Diaz RS, Komninakis S 2009 Toll-like receptor pathway signaling is differently regulated in neutrophils and peripheral mononuclear cells of patients with sepsis, severe sepsis, and septic shock. Crit Care Med 37:132-139

28. Wolfs TG, Dunn-Siegrist I, van't Veer C, Hodin CM, Germeraad WT, van Zoelen MA 2008 Increased release of sMD-2 during human endotoxemia and sepsis: a role for endothelial cells. Mol Immunol 45:3268-3277

29. Akashi S, Saitoh S, Wakabayashi Y, Kikuchi T, Takamura N, Nagai Y, Kusumoto Y, Fukase K, Kusumoto S, Adachi Y 2003 Lipopolysaccharide interaction with cell surface toll-like receptor 4-MD-2: higher affinity than that with MD-2 or CD14. J Exp Med 198:1035-1042

30. Akashi S, Shimazu R, Ogata H, Nagai Y, Takeda K, Kimoto M, Miyake K 2000 Cutting edge: cell surface expression and lipopolysaccharide signaling via the toll-like receptor 4-MD-2 complex on mouse peritoneal macrophages. J Immunol 164:3471-3475

31. Ishihara S, Rumi MA, Kadowaki Y, Kitamura T, Kosugi A, Kimoto M, Miyake K 2002 Essential role of MD-2 in LPS responsiveness and TLR4 distribution. Nat Immunol 3:667-672

32. Kawai T, Adachi O, Ogawa T, Takeda K, Akira S 1999 Unresponsiveness of MyD88-deficient mice to endotoxin. Immunity 11:115-122

33. Ku CL, von Bernuth H, Picard C, Zhang SY, Chang HH, Yang K, Chrabieh M, Issekutz AC, Cunningham CK, Gallin J, Holland SM, Roifman C, Ehl S, Smart J, Tang M, Barrat FJ, Levy O, McDonald D, Day-Good NK, Miller R, Takada H, Hara T, Al-Hajjar S, Al-Ghonaium A, Speert D, Sanlaville D, Li X, Geissmann F, Vivier E, Maródi L, Garty BZ, Chapel H, Rodriguez-Gallego C, Bossuyt X, Abel L, Puel A, Casanova JL 2007 Selective predisposition to bacterial infections in IRAK-4 deficient children: IRAK-4-dependent TLRs are otherwise redundant in protective immunity. J Exp Med 204:2407-2422

34. von Bernuth H, Picard C, Jin Z, Pankla R, Xiao H, Ku CL, Chrabieh M, Mustapha IB, Ghandil P, Camcioglu Y, Vasconcelos J, Sirvent N, Guedes M, Vitor AB Herrero-Mata MJ, Aróstegui JI, Rodrigo C, Alsina L, Ruiz-Ortiz E, Juan M, Fortuny C, Yagüe J, Antón J, Pascal M, Chang HH, Janniere L, Rose Y, Garty BZ, Chapel H, Issekutz A, Maródi L, Rodriguez-Gallego C, Banchereau J, Abel L, Li X Chaussabel D, Puel A, Casanova JL 2008 Pyogenic bacterial infections in humans with MyD88 deficiency. Science 321:691-696

35. Akira S, Takeda K 2004 Toll-like receptor signalling. Nat Rev Immunol 4:499-511

36. Wynn JL, Scumpia PO, Winfield RD, Delano MJ, Kelly-Scumpia K, Barker T, Ungaro R, Levy O, Moldawer LL 2008 Defective innate immunity predisposes murine neonates to poor sepsis outcome but is reversed by TLR agonists. Blood $112: 1750-1758$

37. Wynn JL, Neu J, Moldawer LL, Levy O 2009 Potential of immunomodulatory agents for prevention and treatment of neonatal sepsis. J Perinatol 29:79-88 